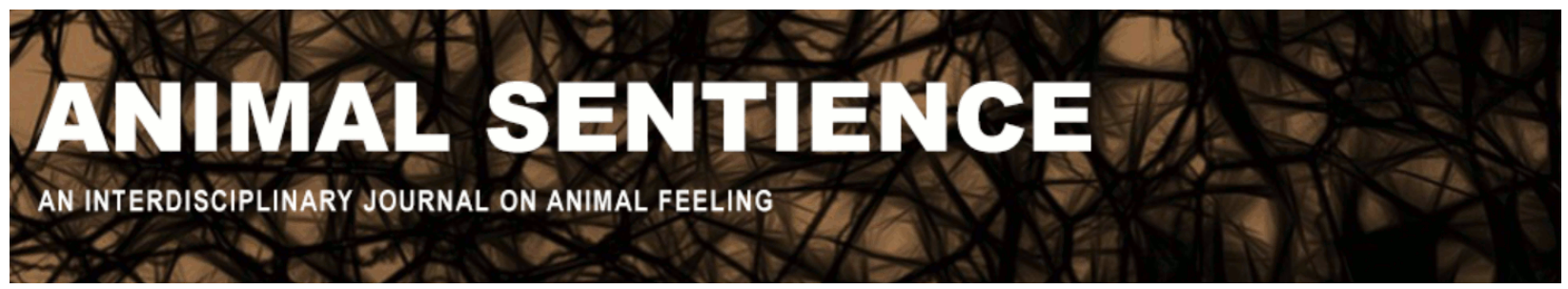

Chapman, Colin A. and Huffman, Michael A. (2019) Diversity on human difference: Unanimity on human responsibility. Animal Sentience 23(51) DOI: $10.51291 / 2377-7478.1511$

Date of submission: 2019-08-17 Date of acceptance: 2019-08-29 (c) 


\title{
Diversity on human difference: Unanimity on human responsibility
}

Response II to Commentary on Chapman \& Huffman on Human Difference

\author{
Colin A. Chapman \\ Dept. of Anthropology, George Washington University \\ Dept. of Anthropology, McGill University \\ Shaanxi Key Laboratory for Animal Conservation \\ School of Life Sciences, University of KwaZulu-Natal
}

Michael A. Huffman

Section of Social Systems Evolution

Primate Research Institute

Kyoto University, Japan

\begin{abstract}
Further commentaries on our original target article add important new points and expand our understanding of the differences between animals, particularly between non-human and human primates. But whether they affirm or deny that humans are unique, all commentators agree that our special abilities mean we should be taking responsibility for the care of nature and the plants and animals it supports. We ask: is humankind doing this?
\end{abstract}

Colin A. Chapman's research focuses on how the environment influences animal abundance and social organization. Given their plight, he has applied his research to conservation. He has conducted research in Kibale National Park in Uganda for 30 years, contributed to the park's development and protection, and has devoted great effort to promoting conservation by helping the rural communities. Website

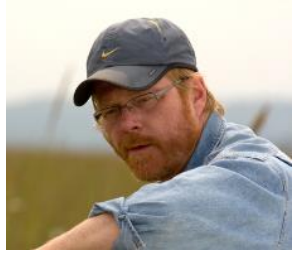

Michael A. Huffman, a tenured faculty member at the Primate Research Institute of Kyoto University, Japan, has published on over 15 primates and other mammals in Japan, Taiwan, Sri Lanka, India, Vietnam, China, Bangladesh, Tanzania, Uganda, Guinea, South Africa, and Brazil. Website

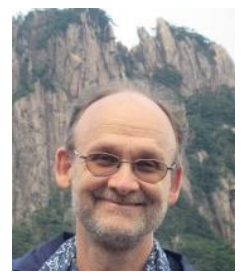

We would once again like to thank all the fifty commentators to date for engaging so thoughtfully with the question of whether humans are fundamentally different from nonhuman animals. We respond here to two new commentaries (Atran; Jung). We also respond to five commentators to whom we failed to respond in the first round (Ball \& Sachs; Juergens; Rogers; Simon; Wilson \& Lehman) and we elaborate our response to some of the prior commentators. 
Atran contends that we "like Darwin, appeal to a seemingly unique moral aptitude that enables humans to be kind to conspecific strangers and other species." He goes on to reflect on whether we consider self-sacrifice to be a unique trait, and then presents his own perspective. We do not think self-sacrifice is a trait unique to humans. We believe that - as with language and tool use - the precursors of self-sacrifice can be seen in non-human animals [cf. Peña-Guzmán, 2017 — ed.]. These precursors are particularly easily observed in non-human primates (hereafter "primates"). Humans build cars and computers, but when chimpanzees use tools or use tools to modify other tools (Matsuzawa, 1991), we view such behaviors as precursors to more advanced tool use. Regarding self-sacrifice: primates will engage in potentially dangerous activities to protect others, including non-kin. Here are two examples from our own observations of wild primates.

In Kibale National Park, Uganda, a young female chimpanzee (Pan troglodytes) had been captured by poachers and was being kept as a pet (Treves and Naughton-Treves, 1997). When she was confiscated by the parks service and an attempt was made to reintroduce her into a wild group of chimpanzees, the males repeatedly charged the person bringing her to the group: a potentially dangerous activity, as the person could have meant them harm. As soon as the infant moved away from the person, the dominant male of the group ran up to within a meter of the human, grabbed her, brought her to his belly - like a female would carry such an infant - and took her to what the male likely perceived as a safer situation; away from the human. The males then cared for and groomed the young female for weeks afterward. Does this not represent self-sacrifice?

A second example involves Cebus monkeys (Cebus spp.), a species that lives in social groups with many males and females; males move between social groups and participate in group defense against predators (Tórrez et al., 2012; Janson, 1986; van Schaik and van Noordwijk, 1989). Even males that have only recently immigrated into the group (hence do not have infants in the group) will vigorously attack predators who are attempting to kill other, often weaker, group members. Does this not represent self-sacrifice? Atran writes that "Humans are above all moral animals because they are creatures who can love their (kin or non-kin) group even more than they love themselves." We leave it to the reader to assess how primates defending the group, as the Cebus monkey example illustrates, bears on Atran's observation. We also ask the reader to ponder how a researcher could verify the feeling of love in animals - perhaps in the light of how dogs often treat a caring owner [cf. Cook et al., 2018 - ed.].

Atran goes on to suggest that "sacred" values lead to very different types of behaviors, including self-sacrifice for no one or no group in particular, adding: "This does not appear to have the faintest echo in the rest of the animal world." What is a sacred value to a chimpanzee? If sacred values cannot be identified, it is not possible to evaluate Atran's assertion. (And are sacred values something of which humans should be proud or ashamed?)

Jung, like earlier commentators (Bar-Hen-Schweiger and Henik; Monsó; Ng; Blystad; Hood and Giddens; McGrew; Juergens; Ball \& Sachs), suggests that differences among species should not be used to imply moral ranking. (We agree.) He goes on to consider that quantity and quality should not be considered different categories; rather, there is a transition between the two. We did not mention quantity vs. quality in our target article, discussing only whether any trait was unique. Comparing tool use in chimpanzees and humans, Jung suggests that somewhere in the evolutionary process that led to humans, there was a leap from quantity to quality in using and making tools. We agree, but this was indeed 
a transition; both species have the trait of tool use. Thus, humans are not unique in possessing the trait; the difference is only in the degree of expression. Humans make tools more. Many animals are now recognized as able do things we thought only humans could do; future research may reveal more (Rogers).

Jung, again like earlier commentators (Wilson \& Lehman; Schoof and L'Allier; Fischer; Rollin) - as well as us in the target article - agree that people have superior abilities to think and use tools, but that we will only have a future if we treat non-human living beings and their environment with "respect and real care." We should keep in mind the skepticism of Simon, who expressed the idea that even if the continuity between species is recognized, knowing that may not be enough to change how we treat them.

Is humankind making advances in caring for animals and their environment? The United States has lately legalized (Lewis, 2019) - then withdrawn (U.S. Environmental Protection Agency (EPA) (2019), then...? - the use of cyanide bombs to kill animals as well as allowed greater contamination of the planet's waterways (Mufson, 2019). Tropical forests are being lost at an accelerating rate (Hansen et al., 2013; Chapman et al., 2018); Brazil's current policies are only accelerating the loss even more (Phillips, 2019). The world's response to climate change is patchy and fundamentally inadequate (Chapman et al., 2019). Scholars need to do more to make their thoughts heard by policy makers and the public.

Acknowledgements: The thoughts expressed in this article were developed from decades of sharing our days with primates in their natural environments on their terms. We would like to thank all the people with whom we shared field experiences and all the people inside and outside the tropical forests we learned from. We are grateful to Selin Altuntur, Elizabeth Donison, Layan Elchaar, Augustine Fuentes, Simon L'Allier, Stevan Harnad, Greg Mikkelson, David Paterson, Rachel Sader, Rachel van Vliet, and Elsie Yan for helpful comments on the ideas presented.

\section{References}

Atran, S. (2019) Superior or inferior, human uniqueness is manifold. Animal Sentience 23(50).

Ball, D. \& Sachs, B. (2019) Scepticism about moral superiority. Animal Sentience 23(46).

Bar-Hen-Schweiger, M. \& Henik, A. (2019) Intelligence as mental manipulation in humans and nonhuman animals. Animal Sentience 23(31).

Blystad, M. H. (2018) Human-like behavior and cognition: Not a good starting point. Animal Sentience 23(11).

Chapman, C. A., Hou, R. \& Kalbitzer, U. (2019) What will climate change mean for primates?. Primatology, Bio-cultural Diversity and Sustainable Development in Tropical Forests. A Global Perspective. pp. 137-151. UNESCO, Mexico City, Mexico.

Chapman, C. A., Omeja, P. A., Kalbitzer, U., Fan, P. \& Lawes, M. J. (2018) Restoration provides hope for faunal recovery: Changes in primate abundance over 45 Years in Kibale National Park, Uganda. Tropical Conservation Science, 11, 1940082918787376.

Cook, P., Prichard, A., Spivak, M. \& Berns, G. S. (2018) Łealousy in dogs? Evidence from brain imaging. Animal Sentience 22(1).

Fischer, B. (2018) Individuals in the wild. Animal Sentience 23(8).

Hansen, M. C., Potapov, P. V., Moore, R., Hancher, M., Turubanova, S. A., Tyukavina, A., Thau, D., Stehman, S. V., Goetz, S. J., Loveland, T. R., Kommareddy, A., Egorov, A., Chini, L., 
Justice, C. 0. \& Townshend, J. R. G. (2013) High-resolution global maps of 21st-century forest cover change. Science, 342, 850-853.

Hood, S. B. \& Giddens, S. (2019) Phenotypic similarity and moral consideration. Animal Sentience 23(35).

Janson, C. (1986) The mating system as a determinant of social evolution in capuchin monkeys (Cebus). Primate Ecology and Conservation, 2, 169-179.

Juergens, U. M. (2018) Human and nonhuman animals: Equals in uniqueness. Animal Sentience 23(2).

Jung, C. (2019) Why cod don't like to sunbathe: Quantity and quality in the animal kingdom. Animal Sentience 23(49).

Lewis, S. (2019) Trump administration reauthorizes use of "cyanide bombs" to kill wild animals. August 19, 2019. CBC News.

Matsuzawa, T. (1991) Nesting cups and metatools in chimpanzees. Behavioral and Brain Sciences, 14, 570-571.

McGrew, W. C. (2019) Humans have always been unique! Animal Sentience 23(28). Monsó, S. (2019) Humans are superior-by human standards. Animal Sentience 23(17). Mufson, S. (2019) Fifteen AGs slam Trump move to limit federal authority under Clean Water Act. Washington Post. Washington.

Ng, Y.-K. (2019) Human superiority is obvious but does not justify cruelty. Animal Sentience 23(36).

Peña-Guzmán, D. M. (2017) Can nonhuman animals commit suicide? Animal Sentience 20(1).

Phillips, T. (2019) Bolsonaro rejects 'Captain Chainsaw' label as data shows deforestation 'exploded'. The Guardian.

Rogers, L. J. (2019) More evidence of complex cognition in nonhuman species. Animal Sentience 23(20).

Rollin, B. (2018) Human superiority? Animal Sentience 23(5).

Schoof, V. A. \& L'Allier, S. (2019) Mobilizing heads and hearts for wildlife conservation. Animal Sentience 23(42).

Simon, C. (2019) Taking Darwinism seriously. Animal Sentience 23(47).

Tórrez, L., Robles, N., González, A. \& Crofoot, M. C. (2012) Risky business? Lethal attack by a jaguar sheds light on the costs of predator mobbing for capuchins (Cebus capucinus). International Journal of Primatology, 33, 440-446.

Treves, A. \& Naughton-Treves, L. (1997) Case study of a chimpanzee recovered from poachers and temporarily released with wild conspecifics. Primates, 38, 315-324.

U.S. Environmental Protection Agency (EPA). (2019) Statement by EPA Administrator Wheeler on M-44, Predator Control Devices.

van Schaik, C. P. \& van Noordwijk, M. A. (1989) The special role of male Cebus monkeys in predation avoidance and its effect of group composition. Behavioral Ecololgy and Sociobiology, 24, 265-276.

Wilson, M. L. \& Lehman, C. L. (2019) Humans: Uniquely responsible for causing conservation problems, uniquely capable of solving them. Animal Sentience 23(19). 